\title{
IN VITRO INTERACTIONS OF COSTUS SPECIOSUS (J. KOENIG) SM., CYMBOPOGON CITRATUS (DC. EX NEES) STAPF. AND TABERNAEMONTANA CORONARIA (L.) WILLD. WITH FIRST- LINE ANTI-TUBERCULOSIS DRUGS AGAINST MYCOBACTERIUM TUBERCULOSIS H37RV
}

\author{
SURIYATI MOHAMAD ${ }^{1}$, NUR NAJIHAH ISMAIL ${ }^{1}$, HASNAH OSMAN ${ }^{2}$, HABIBAH A. \\ WAHAB ${ }^{3}$ AND THAIGARAJAN PARUMASIVAM ${ }^{3 *}$ \\ ${ }^{1}$ School of Biological Sciences, Universiti Sains Malaysia, Pulau Pinang, Malaysia \\ ${ }^{2}$ School of Chemical Sciences, Universiti Sains Malaysia, Pulau Pinang, Malaysia \\ ${ }^{3}$ School of Pharmaceutical Sciences, Universiti Sains Malaysia, Pulau Pinang, Malaysia
}

Published online: 23 November 2021

To cite this article: SURIYATI MOHAMAD, NUR NAJIHAH ISMAIL, HASNAH OSMAN, HABIBAH A. WAHAB \& THAIGARAJAN PARUMASIVAM (2021) In vitro interactions of Costus speciosus (J. Koenig) Sm., Cymbopogon citratus (DC. Ex Nees) Stapf. and Tabernaemontana coronaria (L.) Willd. with first-line anti-tuberculosis drugs against Mycobacterium tuberculosis H37Rv, Malaysian Journal of Pharmaceutical Sciences, 19(2): 171-178. https://doi.org/10.21315/mjps2021.19.2.11

To link to this article: https://doi.org/10.21315/mjps2021.19.2.11

\section{ABSTRACT}

Global tuberculosis (TB) burden underscores the importance of developing new effective anti-TB drugs. This study was concerned with prospecting for potential anti-TB agents from Malaysian medicinal plants. In our previous study, we have reported that n-hexane fractions of Costus speciosus (C. speciosus) (J. Koening) Sm., Cymbopogon citratus (C. citratus ) (DC.) Stapf. and Tabernaemontana coronaria (T. coronaria) (Jacq.) posses promising anti-TB activity against Mycobacterium tuberculosis (M. tuberculosis) H37Rv with minimum inhibitory concentrations (MICs) of 200-100 $\mu \mathrm{g} / \mathrm{mL}$. This study aimed to investigate the interactions of these active fractions with first-line anti-TB drugs (isoniazid, rifampicin, ethambutol and streptomycin) against $M$. tuberculosis H37Rv using the microdilution checkerboard method. C. citratus (stem-rhizome) n-hexane fraction exhibited synergism with all drugs except ethambutol which showed additive interaction. Synergistic was also observed when C. speciosus (stem-flower) n-hexane and T. coronaria (leaf) $n$-hexane fractions in combination with rifampicin. C. speciosus (stem-flower) $n$-hexane and $T$. coronaria (leaf) n-hexane exhibited additive interaction with isoniazid, ethambutol and streptomycin. Hence, these active plants are worthy of further investigations for the discovery of anti-TB drug leads.

Keywords: Plant fractions, Checkerboard, Fractional inhibitory concentration index, Synergism

"Corresponding author: thaigarp@usm.my

(c) Penerbit Universiti Sains Malaysia, 2021. This work is licensed under the terms of the Creative Commons Attribution (CC BY) (http://creativecommons.org/licenses/by/4.0/). 


\section{INTRODUCTION}

Tuberculosis (TB) is an infectious respiratory disease caused by Mycobacterium tuberculosis (M. tuberculosis). The treatment regimens of TB consisting of a combination of several antibiotics instead of monotherapy due to: a) administration of antibiotics cocktail is required because of the different drug sensitivities of the active and latent sub-populations of the TB bacilli in the host tissues, b) combination therapy is used to expand the anti-mycobacterial spectrum of the drugs, to achieve minimum dose, and reduce toxicity, thereby, exhibiting anti-TB activity greater than that expected from each drug individually and c) concurrent administration of a few drugs is often mandatory in rational TB drug therapy in order to achieve the desired therapeutic goal and to treat its common co-existing diseases such as HIV as well as to prevent the development of anti-TB drug resistance (Kerantzas and Jacobs 2017; Parumasivam et al. 2016).

With the advancing increase in the incidence of multidrug-resistant tuberculosis (MDR-TB), ideally, new drugs must be effective against the MDR strains and can be augmented with the existing anti-TB drugs. Hence, in TB drug discovery development, evaluation of the activity of novel combinations of new anti-TB agents, regardless of their origins, with the existing first-line drugs is imperative in order to achieve mycobactericidal synergism.

Like synthetic drugs, sometimes a single plant extract does not produce the desired effective inhibitory effects when alone but when the extracts are taken concurrently with standard drugs, they enhance the effects of that drugs (Williamson 2001). The combinations of the extracts and existing drugs often generate a synergistic effect, which surpasses their individual performance. Many potentially significant advantages are associated with the synergistic interactions of different plant extracts and antibiotics. These advantages include increased efficacy, reduction of side effects and increase in stability or bioavailability of the bioactive constituents, and achieving an adequate therapeutic effect with smaller doses (Hemaiswarya, Kruthiventi and Doble 2008; Inui et al. 2007). The alternative approach of combination therapy of existing drugs and bioactive plant extracts against infectious diseases is a novel concept, which has garnered significant attention.

In our previous studies, we reported that the n-hexane partitions of Costus speciosus (C. speciosus) (J. Koening) Sm., (Local name: Malay ginger; Plant part: stemflower), Cymbopogon citratus (C. citratus ) (DC.) Stapf. (Local name: lemongrass; Plant part: stem-rhizome) and Tabernaemontana coronaria (T. coronaria) (Jacq.) (Local name: crepe jasmine; Plant part: leaf) exhibited potential anti-TB activity with minimum inhibitory concentration (MIC) between $100 \mu \mathrm{g} / \mathrm{mL}$ and $200 \mu \mathrm{g} / \mathrm{mL}$ against M. tuberculosis H37Rv (Mohamad et al. 2018). In the present study, the bacteriostatic activities of these fractions in combination with first-line anti-TB drugs (i.e. isoniazid, rifampicin, ethambutol and streptomycin) were investigated against $M$. tuberculosis H37Rv using the checkerboard method. The study highlights important aspects of drug interaction of increasing the anti-TB activity of individual agents with different combinations of drugs and plant fractions.

\section{METHODS}

\section{Collection, Identification and Plant Partition Preparation}

The collection, identification and plant extract fractionation were performed as described by (Mohamad et al. 2018). Briefly, the plant materials were collected from Pulau Pinang and Kedah, Malaysia. The samples were authenticated and deposited by the Herbarium

Malay J Pharm Sci, Vol. 19, No. 2 (2021): 171-178 
Unit, School of Biological Sciences, Universiti Sains Malaysia. The voucher numbers are 11435, 11152 and 11429 for $C$. speciosus, C. citratus and $T$. coronaria, respectively. The stems and flowers for $C$. speciosus, stems and rhizomes for $C$. citratus and leaves for $T$. coronaria were dried in an oven at $40^{\circ} \mathrm{C}$, pulverised and went through maceration in $80 \%$ methanol at ambient temperature. The crude extract then concentrated under reduced pressure. The crude extracts were fractioned using n-hexane and the partition stored at $4^{\circ} \mathrm{C}$. Prior to the bioassay, the pre-weight extracts and antibiotics were dissolved in dimethyl sulfoxide (DMSO), diluted in a fresh medium to reduce the DMSO concentration $(<1 \% \mathrm{v} / \mathrm{v})$ and filter sterilised.

\section{Drug Combination Plate Preparation}

The interaction study of the fractions with four first-line anti-TB drugs: isoniazid, rifampicin, ethambutol and streptomycin was carried out using the microdilution method, following the checkerboard configuration as described by Eliopoulos and Moellering (1991). Each drugfraction combination test was performed in triplicate using a 6-by-6 well configuration. The working solutions were prepared so that the MIC value for each fraction and drug alone would be at the third well of the two-fold serial dilution. Briefly, in a plate, $50 \mu \mathrm{L}$ of enriched Middlebrook $7 \mathrm{H} 9$ broth was added into all wells except the wells in the first column of the configuration. Then, $50 \mu \mathrm{L}$ of the fraction at four-fold greater than the highest desired final concentration was added into the wells in the first and second columns. A two-fold dilution series of the fraction was made along the x-axis. In another plate, a similar configuration of a drug was prepared simultaneously with the two-fold dilution along the y-axis. Next, the content of each well in the drug plate was transferred into its respective well into the fraction plate. Thus, the final configuration consisted of columns and rows in which, each well contained the same volume of fraction and drug with a uniquely different combination of the fraction and drug. A column of wells containing growth medium without drug/fraction was also included as a control. Then, $100 \mu \mathrm{L}$ of log-phase $M$. tuberculosis H37Rv inoculum was added into all the test wells. The microplates were incubated at $37^{\circ} \mathrm{C}$ in $8 \% \mathrm{CO}_{2}$ for five days. On the fifth day, $50 \mu \mathrm{L}$ of tetrazolium reagent mixture was added into all wells. The plates were re-incubated, and the results were read visually on the following day. The MICs recorded as the lowest concentrations that prevented the colour change of the tetrazolium mixture from yellow to purple.

\section{Determining the Interaction}

The fractional inhibitory concentration index $\left(\sum \mathrm{FIC}\right)$ was calculated to determine the nature of interaction using the following formula:

$$
\sum \mathrm{FIC}=\frac{\mathrm{MIC} \mathrm{Plant}_{\text {fraction combination }}}{\mathrm{MI} \mathrm{C}_{\text {Plant fraction alone }}}+\frac{\mathrm{MIC}_{\text {Drug combination }}}{\mathrm{MIC}_{\text {Drug alone }}}
$$

The results interpreted as follows: synergistic $\left(\sum \mathrm{FIC} \leq 0.5\right)$, additive $\left(0.5<\sum \mathrm{FIC}\right.$ $\leq 1.0)$, indifferent $\left(1.0<\sum F I C \leq 4.0\right)$ and antagonistic $\left(\sum F I C>4.0\right)($ Vambe et al. 2018; van Vuuren and Viljoen 2011). 


\section{RESULTS AND DISCUSSION}

The n-hexane fractions of C. citratus (stem-rhizome), C. speciosus (stem-flower) and $T$. coronaria (leaf) exhibited anti-TB activity with MICs in the range of $100-200 \mu \mathrm{g} / \mathrm{mL}$ (Table 1). The MIC of isoniazid, rifampicin, ethambutol and streptomycin was $0.0625 \mu \mathrm{g} / \mathrm{mL}, 0.125 \mu \mathrm{g} / \mathrm{mL}, 4.0 \mu \mathrm{g} / \mathrm{mL}$ and $1.0 \mu \mathrm{g} / \mathrm{mL}$, respectively, which are in agreement with the previous studies (Burke, Coronel and Moore 2017; Heinrichs et al. 2018). These drugs were chosen because they are essential first-line anti-TB drugs. The treatment with these drugs is carried out initially over two months to kill all active and drug-susceptible TB bacilli (World Health Organization 2010). The treatment then continues with rifampicin and isoniazid for four months to eliminate any residual dormant bacilli (World Health Organization 2010).

Table 1: The MIC of plant fractions and first-line anti-tuberculosis drugs against $M$. tuberculosis H37Rv ATCC 25618.

\begin{tabular}{ll}
\hline Plant fractions and drugs & MIC $(\mu \mathrm{g} / \mathrm{mL})$ \\
\hline C. citratus (stem-rhizome) n-hexane & 200 \\
C. speciosus (stem-flower) n-hexane & 100 \\
T. coronaria (leaf) n-hexane & 100 \\
Isoniazid & 0.0625 \\
Rifampicin & 0.125 \\
Ethambutol & 4.0 \\
Streptomycin & 1.0 \\
\hline
\end{tabular}

The interaction of 12 sets of combinations between the plant fractions and the first-line anti-TB drugs are presented in Table 2. Five out of the 12 combinations produced synergistic $(\Sigma \mathrm{FIC}$ in the range of 0.38 and 0.50$)$ activity with the individual $\mathrm{MIC}$ of the fractions and drugs decreased 4 to 8 folds. Synergistic interaction could result from the differences in the mechanisms of action of the drug and active constituent(s) in the fractions (Eliopoulos and Moellering 1991). According to Pritchard et al. (2013), these successful combinations could elicit lethal effects in which, the inhibition of parallel pathways of the drugs and the bioactive constituents combines to kill the target cells rapidly. Therefore, the plant fractions interacted synergistically with the TB drugs because they contained bioactive constituents that are acting on different targets as compared to the anti-TB drugs. For example, the mechanism of action of the bioactive constituents in $C$. speciosus (stem-flower) n-hexane fraction could not be the inhibition of RNA synthesis by binding to the $\beta$-subunit of the DNAdependent polymerase as rifampicin due to synergistic interaction between this fraction and rifampicin. 
Table 2: Interaction of $C$. citratus, $C$. speciosus and $T$. coronaria fractions with first-line antituberculosis drugs against M. tuberculosis H37Rv ATCC 25618.

\begin{tabular}{|c|c|c|c|c|c|c|}
\hline $\begin{array}{l}\text { Combination } \\
\text { of plant } \\
\text { fractionsand } \\
\text { drugs }\end{array}$ & $\begin{array}{l}\text { Individual } \\
\mathrm{MIC}(\mu \mathrm{g} / \\
\mathrm{mL})\end{array}$ & $\begin{array}{l}\text { Combination } \\
\text { MIC }(\mu \mathrm{g} / \mathrm{mL})\end{array}$ & $\begin{array}{l}\text { Increase } \\
(+) \text { or } \\
\text { decrease (-) } \\
\text { of individual } \\
\text { activity } \\
\text { based on }(-) / \\
(+) \text { of MIC } \\
\text { (folds) }\end{array}$ & $\begin{array}{l}\text { Individual } \\
\text { FIC }\end{array}$ & $\sum \mathrm{FIC}$ & Interactions \\
\hline $\mathrm{CC}^{\mathrm{h}}-\mathrm{INH}$ & $200 / 0.0625$ & $50 / 0.0081$ & $+4 /+7.8$ & $0.25 / 0.13$ & 0.38 & Synergistic \\
\hline$C C^{h}-$ RIF & $200 / 0.125$ & $25 / 0.0312$ & $+8 /+4$ & $0.13 / 0.25$ & 0.38 & Synergistic \\
\hline$C C^{h}-E M B$ & $200 / 4$ & $100 / 0.25$ & $+2 /+16$ & $0.5 / 0.063$ & 0.56 & Additive \\
\hline$C C^{h}-S T R$ & $200 / 1$ & $25 / 0.25$ & $+8 /+4$ & $0.13 / 0.25$ & 0.38 & Synergistic \\
\hline$C S^{h}-I N H$ & $100 / 0.0625$ & $75 / 0.0015$ & $+1.3 /+41.7$ & $0.75 / 0.024$ & 0.77 & Additive \\
\hline$C S^{h}-$ RIF & $100 / 0.125$ & $25 / 0.0312$ & $+4 /+4$ & $0.25 / 0.25$ & 0.50 & Synergistic \\
\hline$C S^{h}-E M B$ & $100 / 4$ & $50 / 1.25$ & $+2+/ 3.2$ & $0.50 / 0.31$ & 0.81 & Additive \\
\hline $\mathrm{CS}^{\mathrm{h}}-\mathrm{STR}$ & $100 / 1.0$ & $50 / 0.25$ & $+2 /+4$ & $0.50 / 0.25$ & 0.75 & Additive \\
\hline $\mathrm{TC}^{\mathrm{h}}-\mathrm{INH}$ & $100 / 0.0625$ & $50 / 0.001$ & $+2 /+62.5$ & $0.50 / 0.016$ & 0.52 & Additive \\
\hline $\mathrm{TC}^{\mathrm{h}}-\mathrm{RIF}$ & $100 / 0.125$ & $12.5 / 0.0312$ & $+8 /+4$ & $0.13 / 0.25$ & 0.38 & Synergistic \\
\hline $\mathrm{TC}^{\mathrm{h}}-\mathrm{EMB}$ & $100 / 4$ & $50 / 0.25$ & $+2 /+16$ & $0.50 / 0.063$ & 0.56 & Additive \\
\hline$T^{h}-S T R$ & $100 / 1.0$ & $50 / 0.125$ & $+2 /+8$ & $0.50 / 0.13$ & 0.63 & Additive \\
\hline
\end{tabular}

Notes: $\mathrm{CC}^{\mathrm{h}}=C$. citratus (stem-rhizome) $\mathrm{n}$-hexane; $\mathrm{CS}^{\mathrm{h}}=C$. speciosus (stem-flower) $\mathrm{n}$-hexane; $\mathrm{TC}^{\mathrm{h}}=T$. coronaria (leaf) n-hexane; INH = isoniazid; RIF = rifampicin; EMB = ethambutol; STR = streptomycin.

Rifampicin produced synergistic interaction with all the plant fractions. This observation is in agreement with the key role of rifampicin in the treatment of TB because of its frequent synergistic interaction with other anti-TB drugs (Chen et al. 2006). Rifampicin is also an appealing candidate for use within synergistic combinations as it is a dose-dependent rather than a time-dependent antibiotic, whereby, optimal synergistic concentrations can be maintained for a minimum period of time (Ramón-García et al. 2011). Even though rifampicin is associated with toxicity (Diacon and Donald 2014), as a benefit of synergism, the minimum therapeutic dose of rifampicin could be used as its toxic side effects can be decreased without compromising its efficacy. As rifampicin is effective on the dormant persisters (Hu et al. 2015), the results also indicate that the plant fractions in synergy with rifampicin would be able to increase the sterilising activity of rifampicin to eliminate the dormant cells. Hence, these plant fractions could be useful in the treatment of latent TB.

On the other hand, 7 out of 12 combinations produced additive interaction with the $\Sigma$ FIC in the range of 0.52 and 0.81 . According to Tallarida (2001), additive interaction occurs when each drug is equally efficacious and the pair has a relative potency that is not significantly different at each efficacy level. In depth investigations need to be carried out to identify the potency of these plant fraction-drug pair.

No indifferent $\left(1.0<\sum \mathrm{FIC} \leq 4.0\right)$ and antagonistic $\left(\sum \mathrm{FIC}>4.0\right)$ interactions were observed for any extracts and antibiotics in combination. In indifferent interaction, the drugs and fractions did not interact with one another in which only one metabolic pathway can be 
the growth-limiting factor for an organism at a time (Yeh et al. 2009). While antagonistic interaction could be due to the similar mechanisms of action of the compounds in the plant fractions and the anti-TB drugs (Eliopoulos and Moellering 1991). Perhaps this could be due to the presence of various compounds in the fractions where each acts on a different target.

\section{CONCLUSION}

The present study highlights the potential use of n-hexane fractions of $C$. speciosus, $C$. citratus and $T$. coronaria as an anti-TB remedy. It suggests the possible use for combinations with the first-line anti-TB drugs. However, the in vitro drug-fraction interactions could not be acknowledged meticulously for predicting the efficiency of these agents in combination in clinical practices against TB, as these interactions can only provide information about synergistic, additive, indifferent or antagonistic actions of the fractions and drugs in inhibiting the mycobacterial growth. While in vivo combinations may lead to alteration of pharmacokinetics, deterioration of efficacy and modification of toxicity levels of the fractions and drugs. Therefore, these combinations should be further assessed with in vivo studies for clinical significance against TB.

\section{ACKNOWLEDGEMENTS}

The project was funded by the USM short-term grant (304/PFARMASI/63151100).

\section{REFERENCES}

BURKE, R. M., CORONEL, J. \& MOORE, D. (2017) Minimum inhibitory concentration distributions for first- and second-line antimicrobials against Mycobacterium tuberculosis, Journal of Medical Microbiology, 66(7): 1023-1026. https://doi.org/10.1099/jmm.0.000534

CHEN, P., GEARHART, J., PROTOPOPOVA, M., EINCK, L. \& NACY, C. A. (2006) Synergistic interactions of SQ109, a new ethylene diamine, with front-line antitubercular drugs in vitro, Journal of Antimicrobial Chemotherapy, 58(2): 332-337. https://doi. org/10.1093/jac/dkl227

DIACON, A. H. \& DONALD, P. R. (2014) The early bactericidal activity of antituberculosis drugs, Expert Review of Anti-Infectective Therapy, 12(2): 223-237. https://doi.org/10.1586 /14787210.2014.870884

ELIOPOULOS, G. M. \& MOELLERING, R. C. (1991) Anti-microbial combinations. IN: V. Lorian (Ed.). Antibiotics in laboratory medicine, pp. 432-492 (Baltimore: Williams \& Wilkins Co.).

HEINRICHS, M. T., MAY, R. J., HEIDER, F., REIMERS, T., SY, S. K. B., PELOQUIN, C. A. et al. (2018) Mycobacterium tuberculosis strains H37ra and H37rv have equivalent minimum inhibitory concentrations to most antituberculosis drugs, International Journal of Mycobacteriology, 7(2): 156-161. https://doi.org/10.4103/ijmy.ijmy_33_18

Malay J Pharm Sci, Vol. 19, No. 2 (2021): 171-178 
HEMAISWARYA, S., KRUTHIVENTI, A. K. \& DOBLE, M. (2008) Synergism between natural products and antibiotics against infectious diseases, Phytomedicine, 15(8): 639652. https://doi.org/10.1016/j.phymed.2008.06.008

HU, Y., LIU, A., ORTEGA-MURO, F., ALAMEDA-MARTIN, L., MITCHISON, D. \& COATES, A. (2015) High-dose rifampicin kills persisters, shortens treatment duration, and reduces relapse rate in vitro and in vivo, Frontiers in Microbiology, 6(641). https://doi.org/10.3389/ fmicb.2015.00641

INUI, T., WANG, Y., DENG, S., SMITH, D. C., FRANZBLAU, S. G. \& PAULI, G. F. (2007) Counter-current chromatography based analysis of synergy in an anti-tuberculosis ethnobotanical, Journal of Chromatography A, 1151(1-2): 211-215. https://doi. org/10.1016/j.chroma.2007.01.127

KERANTZAS, C. A. \& JACOBS, W. R. (2017) Origins of combination therapy for tuberculosis: Lessons for future antimicrobial development and application, mBio, 8(2): e01586-e01600. https://doi.org/10.1128/mBio.01586-16

MOHAMAD, S., ISMAIL, N. N., PARUMASIVAM, T., IBRAHIM, P., OSMAN, H. \& A WAHAB, $\mathrm{H}$. (2018) Antituberculosis activity, phytochemical identification of Costus speciosus (J. Koenig) Sm., Cymbopogon citratus (DC. Ex Nees) Stapf., and Tabernaemontana coronaria (L.) Willd. and their effects on the growth kinetics and cellular integrity of Mycobacterium tuberculosis H37Rv, BMC Complementary and Alternative Medicine, 18(1): 5-5. https://doi. org/10.1186/s12906-017-2077-5

PARUMASIVAM, T., CHANG, R. Y. K., ABDELGHANY, S., YE, T. T., BRITTON, W. J. \& CHAN, H.-K. (2016) Dry powder inhalable formulations for anti-tubercular therapy, Advanced Drug Delivery Reviews, 102: 83-101. https://doi.org/10.1016/j.addr.2016.05.011

PRITCHARD, J. R., BRUNO, P. M., GILBERT, L. A., CAPRON, K. L., LAUFFENBURGER, D. A. \& HEMANN, M. T. (2013) Defining principles of combination drug mechanisms of action, Proceedings of the National Academy of Sciences, 110(2): E170-E179. https://doi. org/10.1073/pnas.1210419110

RAMÓN-GARCÍA, S., NG, C., ANDERSON, H., CHAO, J. D., ZHENG, X., PFEIFER, T. et al. (2011) Synergistic drug combinations for tuberculosis therapy identified by a novel high-throughput screen. Antimicrobial Agents and Chemotherapy, 55(8): 3861-3869. https://doi.org/10.1128/aac.00474-11

TALLARIDA, R. J. (2001) Drug synergism: Its detection and applications, Journal of Pharmacology and Experimental Theraoeutics, 298(3): 865-872.

VAMBE, M., AREMU, A. O., CHUKWUJEKWU, J. C., FINNIE, J. F. \& VAN STADEN, J. (2018) Antibacterial screening, synergy studies and phenolic content of seven South African medicinal plants against drug-sensitive and -resistant microbial strains, South African Journal of Botany, 114: 250-259. https://doi.org/10.1016/j.sajb.2017.11.011

VAN VUUREN, S. \& VILJOEN, A. (2011) Plant-based antimicrobial studies - Methods and approaches to study the interaction between natural products, Planta Medica, 77(11): 1168-1182. 
WORLD HEALTH ORGANIZATION (2010) Treatment of tuberculosis: Guidelines for national programmes, 4th edition (Geneva: World of Health Organization).

WILLIAMSON, E. M. (2001) Synergy and other interactions in phytomedicines, Phytomedicine, 8(5): 401-409. https://doi.org/10.1078/0944-7113-00060

YEH, P. J., HEGRENESS, M. J., AIDEN, A. P. \& KISHONY, R. (2009) Drug interactions and the evolution of antibiotic resistance, Nature Reviews Microbiology, 7(6): 460-466. https:// doi.org/10.1038/nrmicro2133 